\section{A Bucco-hypophysial Canal in Elops saurus}

A PERststent Rathke's pouch in the form of a hollow bucco-hypophysial canal piercing the parasphenoid bone has been reported in young animals and adults of the two recent brachiopterygian genera Calamoichthys $^{1}$ and Polypterus ${ }^{2,3}$. The recent coelacanthid Latimeria is reported to possess a partly hollow cord of glandular tissue running from the adenohypophysis towards the roof of the mouth cavity $^{4}$. Besides, there is a canal in the parasphenoid, but this canal, which is regarded as a vestige of Rathke's pouch, does not reach the fossa hypophyseos $^{5}$. In the early fossil coelanthids the fossa hypophyseos is in communication with the mouth cavity by means of a canal piercing the parasphenoid and the same is true of the Devonian rhipidistid crossopterygians $^{6}$. In the fossil actinopterygians this communication is rarely retained and has been observed in a few instances only ${ }^{7-9}$. In the recent actinopterygians it has been hitherto unknown.

It was very surprising, therefore, to find a wide canal connecting the pituitary and the oral epithelium in young individuals of the primitive teleost Elops saurus (Fig. 1). No doubt this canal, which strongly resembles that of Polypterus, represents a rudiment of the original pharyngeal pouch.

The canal originates at the anterior end of the adenohypophysis from several follicle-like pockets, which contain tall cells, apparently with glandular properties. In its proximal part, the canal is directed straight ventralwards until it reaches the parasphenoid. There the lumen becomes narrower and the canal turns at right angles rostrally and slightly ventrally, before passing obliquely through the parasphenoid. Underneath this bone the canal opens into the pharynx as an elongated but rather narrow cleft.

The bucco-hypophysial canal is lined by a single. layered squamous epithelium, which nowhere carries cilia, in contrast to the condition in Polypterus, where a strongly ciliated region is found around the opening into the pharynx. The whole apparatus strongly

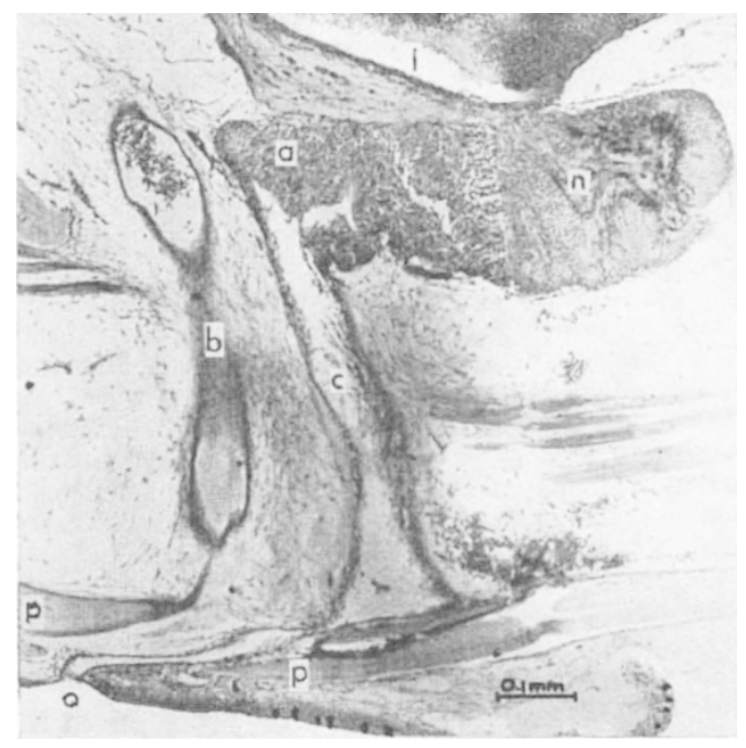

Fig. 1. Elops saurus, $60 \mathrm{~mm}$. median section through the pituitary region showing : $a$, sdenohypophysis; $b$, blood vessel; $c$, buccoypophysial canal ; $i$, infund bulum; $n$, neurohypophysis; suggests a mechanism for external secretion; but no trace of secretion could be seen in the canal lumen of the specimens investigated.

There can be scarcely any doubt that the existence of a persistent communication between the pituitary and the roof of the pharynx is an archaic feature, which may possibly even recall the condition in the ascidians ${ }^{10}$. Anyhow, this observation further strengthens the opinion ${ }^{11}$ that the members of the family Elopidae are the most archaic of the recent teleosts. At the same time it recalls the recent suggestion $^{12}$ that the elopids are holosteans rather than teleosts.

Zootomical Institute,

R. OLsson

University of Stockholm. Oct. 13.

'Bickford, E. E., Anat. Anz., 10, 465 (1895).

2 Budgett Mem. Vol. (Cambridge Univ. Press, 1907).

${ }^{3}$ Gérard, P., and Cordier, R., Ann. Soc, Roy. Zool. Belg., 67, 87 (1937).

"Millot, J., and Anthony, J., “Traité de Zool.", 13, 3 (1958).

"Millot, J., and Anthony, J., "Anatomie de Latimeria chalumnae" (Paris, 1958).

${ }^{6}$ Jarvik, E., K. Sv. Vetenskapsak. Handl., Ser. 4, 5 (1954).

'Stensiö, E., K. Sv. Vetenskapsak. Handl., Ser. 3, 2 (1925).

${ }^{8}$ Stensiö, E., Medd. om Gronland, 83 (1932).

'Rayner, D., Trans. Roy. Soc., 62, 53 (1951).

${ }^{10}$ Julin, C., Arch. Biol., 2, 39 (1881).

"Hollister, G., Zoologica, 21, 257 (1936).

1" Nybelin, O., K. Sv. Vetenskapsak., Ark. Zool., Ser. 2, 10, 453 (1956).

\section{Soluble Nucleotides and Nucleotide-Amino- Acid Compounds of Yeast}

AN investigation of the soluble nucleotides in food yeast (Torulopsis utilis) has shown that a complex metabolic pool of these compounds is maintained in growing cells. Marked changes in the size and composition of this pool under different physiological conditions indicate that the metabolism of nucleotides is closely related to the biosynthesis of nucleic acids and proteins. Some evidence has been obtained that, in exponentially growing cells, certain of the nucleotides occur in combination with amino-acids or simple peptides.

Soluble nucleotides were extracted from yeast by means of jce-cold 60 per cent ethyl alcohol. After removal of the solvent by evaporation in vacuo, and filtration to free the extract from lipid material, the nucleotides were separated by column chromatography on the basic exchange resin 'Dowex-1' $(\times 10)$. The general method of preparation and operation of the column followed that of Brumm, Potter and Siekevitz ${ }^{1}$ except that the elution gradient was steepened by reducing the mixing volume in two stages. In this way, improved separation and sharper peaks were obtained in the later stages of elution. A typical example of the separations achieved by this method is shown in Fig. 1. Identification of the nucleotide peaks is based on co-chromatography with pure compounds, where available, and on measurements of ultra-violet absorption spectra under acid and alkaline conditions.

The elution pattern shown has been consistently observed when cells, in the exponential phase of growth, were rapidly separated from the culture medium by filtration and immediately treated with ice-cold absolute alcohol. Prompt harvesting and fixation are important, since otherwise marked changes oecur in the nucleotide pool. For example, 